\title{
$\begin{array}{ll}\text { Research Square } & \begin{array}{l}\text { Preprints are preliminary reports that have not undergone peer review. } \\ \text { They should not be considered conclusive, used to inform clinical practice, } \\ \text { or referenced by the media as validated information. }\end{array}\end{array}$
}

\section{Influence of Anodization Parameters on Film Thickness and Volume Expansion of Thick and Large-Sized Anodic Aluminum Oxide Film}

\author{
Yuanjing Pu \\ Nanjing Tech University \\ Jiajun $\mathrm{Hu}$ \\ Nanjing Tech University \\ Taicang Yao \\ Nanjing Tech University \\ Linfeng Li \\ Nanjing Tech University \\ Jie Zhao \\ Nanjing Tech University \\ Yu Guo (D mguoyu@njtech.edu.cn ) \\ Nanjing Tech University https://orcid.org/0000-0003-0289-7627
}

Original Research

Keywords: Anodic aluminum oxide, Film thickness, Volume expansion factor, Anodization parameter, Catalyst support

Posted Date: February 12th, 2021

DOI: https://doi.org/10.21203/rs.3.rs-186935/v1

License: (c) (1) This work is licensed under a Creative Commons Attribution 4.0 International License. Read Full License 


\section{Abstract}

Anodic aluminum oxide (AAO) film with a thickness ranging from 20 to $100 \mu \mathrm{m}$ was prepared by using a large-sized Al plate $(4 \mathrm{~cm} \times 10 \mathrm{~cm})$ to investigate the anodization parameter effect on the film thickness and volume expansion factor. A corrosion treatment (voltage $=0 \mathrm{~V}$ ) was performed to investigate the film dissolution caused by acid. The actual anode surface temperature was also measured to confirm the field-assisted nature of AAO dissolution. The film thickness increases exponentially with temperature, and increases approximately linearly with voltage, duration or concentration. The volume expansion factor gives a first rising and then falling trend with temperature or duration, while it has a nearly linear trend with voltage or concentration. The volume expansion factor increases with the intensified electric field, while its decrease is attributed to the Joule heat-enhanced dissolution. In the case of large film thickness $(>20 \mu \mathrm{m})$, the pore confinement effect may be one of the reasons for the change of volume expansion factor. In addition to the conventional parameters, the heat transfer-related parameters such as sample size also greatly affect the AAO film growth.

\section{Introduction}

In the past decade, due to thinner wall thickness, higher thermal conductivity and stronger mechanical strength, metallic-monolith catalyst (MMC) support made of stainless steel or FeCrAl is considered as a potential alternative to the conventional cordierite monolithic catalyst support [1-2]. However, the huge difference in thermal expansion coefficient makes the catalyst coating layer easy to peel from the metal substrate, which is recognized to be the main bottleneck of MMC prepared by the conventional coating method. Using self-growing metal oxide film from metal substrates instead of the conventional coating layer is considered to be a promising method for developing novel MMC catalyst supports. Among them, the anodic aluminum oxide (AAO) film derived from the in-situ self-growth of the Al substrate has received increasing attention, because of the high adhesion between the AAO film and the unoxidized substrate, the high-density pore structure and the controllable preparation parameters. For example, Hong et al. [3] used a AAO material shaped into $\theta$-ring to prepare Pd-based catalyst for ethylanthraquinone hydrogenation. They reported that $\mathrm{Pd}$-based $\mathrm{AAO}$ catalyst exhibited higher productivity than spherical $\mathrm{Pd} / \mathrm{Al}_{2} \mathrm{O}_{3}$ catalyst due to the advantages in mass/heat transfer and confinement effect of cylindrical pores. Some relevant research groups [3-7] and our group [8-11] applied the novel MMC catalyst support to various fields such as hydrogenation reaction [3], steam reforming of methanol [4], Suzuki cross-coupling reaction [5], Fischer-Tropsch synthesis [6], VOCs combustion [7] and steam reforming of methane [11].

As a catalyst support, the chemical properties, pore structure, specific surface area, and film thickness of AAO materials will greatly affect its catalytic performance. In our previous work [12], the modification of pore morphology and chemical properties has been studied by using AAO film with a thickness of 50 $100 \mu \mathrm{m}$ and a pore diameter of $30 \sim 70 \mathrm{~nm}$. The combination of pore widening treatment (immersing in acid solution) and hydrothermal treatment could convert amorphous skeleton alumina into $y$-alumina and change its smooth and parallel tube-like pore structure into a two-dimensional pore structure with a 
larger specific surface area. This present work focuses on investigating the influence of anodization conditions on the film thickness and volume expansion factor of the AAO film, with the goal of achieving highly-controlled AAO film growth.

Relevant literature [13-16] indicated that the important controllable parameters affecting the preparation of AAO thin film were anodization voltage or current density, electrolyte type/concentration, anodization temperature and duration [13]. For example, controlling the anodization voltage can lead to an exponential increase in pore size and interpore distance. Changing the anodization voltage or duration can adjust its film thickness [15-16]. Nevertheless, when an AAO film is used as a catalyst support, how to manufacture an AAO film with a large size and a suitable film thickness is still considered to be a difficult problem. Although the pore and film thickness can be adjusted by changing the preparation conditions, it is inevitable that the AAO film will be corroded under high anodization voltage or for long duration, especially the large-sized and thick AAO film. In other words, due to the serious corrosion problem of large-sized and thick AAO film under high anodization voltage, it is difficult to maintain stable anodization without "burning" the AAO film [14]. Therefore, in many relevant literatures investigating film thickness and volume expansion, small-sized sample and thin film thickness are widely adopted, for example, sample size of $0.75 \mathrm{~cm} \times 0.75 \mathrm{~cm}$ and film thickness of about $2 \mu \mathrm{m}$ in the literature [17], sample size of $1 \mathrm{~cm} \times 1 \mathrm{~cm}$ and film thickness of $<10 \mu \mathrm{m}$ in the literature [18], sample size of $1.2 \mathrm{~cm}^{2}$ and film thickness of about $4 \mu \mathrm{m}$ in the literature [19]. However, for AAO film to replace conventional catalyst coating layer, a thickness of several tens of microns is necessary. Otherwise a film thickness of several microns will greatly increase the amount of catalyst and the reactor volume.

In addition, impurities in the aluminum substrate also have a significant influence on the pore distribution and uniformity of the AAO film. Due to continuous Joule-heating effect, many AAO films are potentiostatically fabricated from high-purity $(>99.99 \%)$ Al substrates at low temperatures of $0 \sim 5^{\circ} \mathrm{C}[20]$. Zaraska et al. [15] reported a faster film thickness growth rate on low-purity aluminum (AA1050, 99.5\%) than high-purity aluminum in $0.3 \mathrm{M}$ oxalic acid and at $20^{\circ} \mathrm{C}$ and $45 \mathrm{~V}$. They proposed that the change in the Joule heat caused by the oxidation of Si impurities was the main reason.

In the present study, a AAO film is prepared by using a large-sized aluminum plate $(4 \mathrm{~cm} \times 10 \mathrm{~cm})$ with a low-purity (99.5\%), and the expected film thickness is about $20 \sim 100 \mu \mathrm{m}$. The influence of the preparation parameters on the thickness and volume expansion is investigated by varying the anodization conditions (voltage, duration, temperature and concentration), in order to find the interaction between these anodization parameters and determine controllable parameters for preparing AAO film into catalyst support.

\section{Experimental}

A commercial aluminum plate (A1050, 99.5\% purity, $0.3 \mathrm{~mm}$ thickness) with a size of $4 \mathrm{~cm} \times 15 \mathrm{~cm}$ was used as the starting material. The aluminum substrate was annealed at $500^{\circ} \mathrm{C}$ and for $3 \mathrm{~h}$. The annealed sample was treated in $4 \mathrm{wt} \%$ sodium hydroxide for $4 \mathrm{~min}$, and $4 \mathrm{wt} \%$ nitric acid and for $1 \mathrm{~min}$, and then 
washed with deionized water. The resulting sample was chemically polished in a mixture of $\mathrm{H}_{3} \mathrm{PO}_{4}, \mathrm{HNO}_{3}$ and $\mathrm{H}_{2} \mathrm{SO}_{4}$ (40:3:7 in weight) at $105^{\circ} \mathrm{C}$ and for 25 seconds. Next, the samples were washed sequentially with sodium hydroxide, nitric acid, and deionized water.

A self-made square water tank (50 cm side length) was used for anodization treatment. The distance between the anode in the middle and the cathode graphite plates on both sides was $20 \mathrm{~cm}$. Two waterproof heating rods $(1 \mathrm{~kW})$ were placed in the electrolyzer to adjust the electrolyte temperature. An external circulating cooler $\left(2000 \mathrm{~L} \cdot \mathrm{h}^{-1}\right)$ was utilized to cool the electrolyte and enhance the temperature consistency in the electrolyzer.

A two-step procedure was adopted to anodize the pre-treated aluminum plate in oxalic acid solution and under constant voltage mode. The sample size immersed in the electrolyte during the anodization process was set to $4 \mathrm{~cm} \times 10 \mathrm{~cm}$. After the first anodization for $2 \mathrm{~h}$, the obtained sample was placed in a mixed acid of $1.8 \% \mathrm{H}_{2} \mathrm{CrO}_{4}$ and $6 \% \mathrm{H}_{3} \mathrm{PO}_{4}$ to remove the pre-anodized layer. After that, a second anodization was carried out. Except for the anodization duration, the preparation conditions for the first anodization and the second anodization remain the same. After the second anodization, the prepared sample was naturally dried for $12 \mathrm{~h}$, and then calcined at $350^{\circ} \mathrm{C}$ and for $1 \mathrm{~h}$ to remove residual oxalic acid. The influence of anodization parameters on the AAO film growth was examined by varying anodization voltage $(20 \sim 60 \mathrm{~V})$, duration time $(2 \sim 16 \mathrm{~h})$, oxalic acid concentration $(2 \sim 8 \mathrm{wt} \%)$, and electrolyte temperature $\left(5 \sim 30^{\circ} \mathrm{C}\right)$.

The plate-type AAO sample was fixed with resin and polished carefully. A microscope was used to determine the film thickness (as shown in Fig. 1). The volume expansion factor is the ratio of the volume (thickness) of the AAO film to the volume (thickness) of aluminum consumed. In Fig. 1, the volume expansion factor is equal to (L2-L3)/(L1-L3). Morphology of the AAO sample was examined by a scanning electron microscope (SEM, S-4800, Hitachi Ltd.).

\section{Results And Discussion}

\subsection{Effect of anodization voltage and duration on AAO film thickness}

Figure 2 shows the influence of anodization voltage on the AAO film thickness ( $4 \mathrm{wt} \%$ oxalic acid, $20^{\circ} \mathrm{C}$ ). When the anodization duration is the same ( $4 \mathrm{~h}, 6 \mathrm{~h}$ or $10 \mathrm{~h})$, the AAO film thickness increases approximately linearly as the voltage increases from $20 \mathrm{~V}$ to $60 \mathrm{~V}$. A longer anodization time produces a greater film thickness growth rate. The film thickness growth rate is $1.32 \mu \mathrm{m} / \mathrm{V}$ for $4 \mathrm{~h}$ anodization, 1.74 $\mu \mathrm{m} / \mathrm{V}$ for $6 \mathrm{~h}$ anodization, and $2.23 \mu \mathrm{m} / \mathrm{V}$ for $10 \mathrm{~h}$ anodization. Note that the ratio of the film thickness growth rate under different anodization duration is not equal to the ratio of the anodization duration, indicating that the duration effect on the film thickness is not a simple linear relationship. 
The influence of anodization duration on the AAO film thickness is shown in Fig. 3 (4 wt\% oxalic acid, $\left.20^{\circ} \mathrm{C}\right)$. When the anodization voltage is the same $(20 \mathrm{~V}, 40 \mathrm{~V}$ or $60 \mathrm{~V})$, as the anodization duration is prolonged from 2 to $16 \mathrm{~h}$, the film thickness first increases approximately linearly and then the rising speed gradually slows down. The initial film thickness growth rate is calculated by using the data within $6 \mathrm{~h}$, and it is $2.90 \mu \mathrm{m} / \mathrm{h}$ for $20 \mathrm{~V}, 6.12 \mu \mathrm{m} / \mathrm{h}$ for $40 \mathrm{~V}$, and $10.71 \mu \mathrm{m} / \mathrm{h}$ for $60 \mathrm{~V}$. That is, a higher voltage results in a thicker film thickness and a higher initial film thickness growth rate. The initial linear growth is similar to the results reported in relevant literature $[15,21]$. For instance, Zaraska et al. [15] gave an ideal linear film thickness growth with a slope of $9.46 \mu \mathrm{m} / \mathrm{h}\left(0.3 \mathrm{M}\right.$ oxalic acid, $\left.45 \mathrm{~V}, 20^{\circ} \mathrm{C}\right)$. On the other hand, it is also found that higher voltage causes the film thickness to deviate more rapidly from the linear relationship with time. More specifically, when the voltage is $20 \mathrm{~V}$, a favorable linear relationship can be maintained well until $10 \mathrm{~h}$. However, it is $8 \mathrm{~h}$ at $40 \mathrm{~V}$, and $6 \mathrm{~h}$ at $60 \mathrm{~V}$. In addition, on the AAO sample anodized at $60 \mathrm{~V}$ and for $16 \mathrm{~h}$, it is found that the ordered porous morphology is destroyed, and flocculated deposits appear on its surface (not shown here).

Figure 4 shows an example of current variation during anodization process ( $40 \mathrm{~V}, 4 \mathrm{wt} \%$ oxalic acid, $20^{\circ} \mathrm{C}$ ). In the initial $1 \mathrm{~min}$ of the constant voltage mode, the current fluctuates violently, which is associated with the formation of the barrier oxide layer [22]. Next, the anodization current reaches a peak value and then slowly decreases during the subsequent $6 \mathrm{~h}$ oxidation process. A similar current trend (oxalic acid, $40 \mathrm{~V}, 18^{\circ} \mathrm{C}$ ) was given in the literature [23]. Regarding the reduced current (or current density), the seemingly simple and reasonable explanation is that the increased film thickness increases its resistance. It is generally accepted that the AAO film thickness is defined by anodization time and current density according to Faraday law. Therefore, the gradual decrease in current during the anodization process seems to be an appropriate explanation for the depressed film thickness growth rate shown in Fig. 3. Shang et al. [23] researched the preparation of uniform pore structure in oxalic acid solution through voltage compensation mode. They proposed that in the traditional AAO preparation method, as the anodization duration prolonged, the pore length gradually increased, and the ion concentration (directly involved in oxidation) in the front of the pore would reduce gradually, resulting in a decrease in current. Belwalkar et al. [21] also reported similar research conclusions.

\subsection{Effect of electrolyte temperature and electrolyte concentration on volume expansion factor}

This section examines the influence of electrolyte temperature and concentration on the AAO film thickness and volume expansion factor. Figure 5 shows the changes of AAO film thickness, volume expansion factor and current density with electrolyte temperature ( $4 \mathrm{wt} \%$ oxalic acid, $40 \mathrm{~V}, 6 \mathrm{~h}$ ). The current density in Fig. 5 is calculated based on the average current in the initial $2 \sim 4$ min of the anodization process (as shown in Fig. 4).

When the electrolyte temperature increases from 5 to $30^{\circ} \mathrm{C}$, the current density increases almost exponentially. The change trend of film thickness is roughly similar to the current density, although it becomes more linear when temperature exceeds $20^{\circ} \mathrm{C}$. This synchronization indicates that the increase in 
film thickness may be related to the exponential increase in current density caused by the increase in electrolyte temperature. On the other hand, despite the continuous increase in film thickness, the volume expansion factor first increases from 1.21 at $5^{\circ} \mathrm{C}$ to 1.28 at $10^{\circ} \mathrm{C}$, and then gradually drops to 1.13 at $30^{\circ} \mathrm{C}$. Kao et al. [19] investigated the influence of phosphoric acid electrolyte temperature $\left(0 \sim 7^{\circ} \mathrm{C}, 10\right.$ $\mathrm{wt} \%, 160 \mathrm{~V}$ ) on the volume expansion factor of AAO film. Similar to the result shown in Fig. 5 , as the temperature of phosphoric acid increased, the current density and film thickness increased almost synchronously, but the volume expansion factor first rose gradually $\left(0 \sim 5^{\circ} \mathrm{C}\right)$ and then dropped rapidly $(5$ $\left.\sim 7^{\circ} \mathrm{C}\right)$.

According to the results in Fig. 5 and the relevant literature [17, 19, 21], the increase in volume expansion factor within 5 to $10^{\circ} \mathrm{C}$ should be attributed to the increase in current density caused by the enhanced electrolyte temperature. It was reported that the increased electrolyte temperature accelerated the ionization of aluminum at the oxide/aluminum interface [19]. Simultaneously, as the electrolyte temperature increased, the concentration of hydroxide and oxygen ions from the hydrolysis of the conjugate base of the acids would also increase at the oxide/electrolyte interface, which intensified the diffusion and drift across the oxide layer and formation of $\mathrm{Al}_{2} \mathrm{O}_{3}$ with $\mathrm{Al}^{3+}$ at the oxide/aluminum interface [19]. The promoted aluminum ionization and the increased $\mathrm{O}^{2-} / \mathrm{OH}^{-}$ion concentration led to the increase in current. Belwalkar et al. [21] proposed that the increased current provided greater impetus for larger volume expansion, and thereby pushed more oxide up the walls, resulting in higher thickness. Similarly, Vrublevsky et al. [17] reported that the volume expansion factor depended on the electric field strength in the barrier layer, and the increase in electric field strength in the barrier layer resulted in the increase of volume expansion factor.

It is generally accepted that the AAO film thickness is dictated by dynamic equilibrium of oxidation and chemical dissolution $[13,21]$. More specifically, the growth mechanism of the AAO film depends on the equilibrium between the oxide formation at the metal/oxide interface and the oxide dissolution at the electrolyte/oxide interface [13]. The reactions involved in the electrochemical anodization process are shown as follows: 1) $2 \mathrm{Al}+3 \mathrm{H}_{2} \mathrm{O} \rightarrow \mathrm{Al}_{2} \mathrm{O}_{3}+6 \mathrm{H}^{+}+6 \mathrm{e}$ (oxidation at anode); 2 ) $\mathrm{Al}_{2} \mathrm{O}_{3}+6 \mathrm{H}^{+} \rightarrow 2 \mathrm{Al}^{3+}+3 \mathrm{H}_{2} \mathrm{O}$ (dissolution at anode); 3) $6 \mathrm{H}^{+}+6 \mathrm{e} \rightarrow 3 \mathrm{H}_{2}$ (at cathode). Belwalkar et al. [21] proposed that the dynamic equilibrium of the oxide formation (highly dependent on the acid concentration and availability of oxygen ions) and dissolution (relatively constant due to its field-assistant nature) caused a characteristic limiting thickness [21]. Accordingly, it is possible that the oxide dissolution is responsible for the decreased volume expansion factor within $10^{\circ} \mathrm{C}$ to $30^{\circ} \mathrm{C}$ shown in Fig. 5 .

Herein, an approximate corrosion experiment was performed to investigate the influence of the AAO film dissolution caused by the acidic electrolyte on the volume expansion factor. After the secondary anodization, the voltage was adjusted to $0 \mathrm{~V}$, and the resulting AAO sample was continuously immersed in the original electrolyte for the same time as the secondary oxidation (electrolyte conditions remain unchanged). The corrosion effect was investigated by using the film thickness variation before and after corrosion treatment. 
As shown in Fig. 5, immersing the prepared AAO sample in acidic electrolyte results in a film thickness loss. Below $20^{\circ} \mathrm{C}$, the film thickness loss is not remarkable. When the AAO sample is subjected to the corrosion treatment above $20^{\circ} \mathrm{C}$, the film thickness loss almost increases exponentially with the electrolyte temperature. It is acceptable that at temperatures below $20^{\circ} \mathrm{C}$ weak corrosion causes the film thickness and current density to increase synchronously and exponentially. At temperatures higher than $20^{\circ} \mathrm{C}$, however, strong corrosion breaks the synchronization between film thickness growth and current density, and the film thickness growth rate deviates from the current increase rate under the combined effect of current density and corrosion. In other words, the strengthened alumina dissolution above $20^{\circ} \mathrm{C}$ is believed to be the main reason for the decreased volume expansion factor in the range of $10 \sim 30^{\circ} \mathrm{C}$.

The changes of film thickness (after anodization or after corrosion treatment), current density and volume expansion factor with electrolyte concentration are shown in Fig. 6. Increasing the electrolyte concentration from 2-8\% causes the current density and the film thickness increase slowly and synchronously, but the increase amplitude is much weaker than the case of adjusting the electrolyte temperature. The increased electrolyte concentration also slightly promotes the corrosion treatment effect after anodization. The enhanced ion concentration caused by the increased electrolyte concentration is considered to be responsible for the approximately linear increase of current density. Simultaneously, since the film thickness produced by anodic oxidation or the film thickness loss caused by corrosion treatment increases approximately linearly with the electrolyte concentration, the volume expansion factor also shows a linear change trend. Kao et al. [19] investigated the influence of phosphoric acid concentration on the volume expansion factor, and provided a first rising and then dropping trend. Different conclusions should be associated with different anodization conditions. It is well known that the electrolyte type greatly affects the AAO film morphology. Due to the strong corrosiveness of phosphoric acid, phosphoric acid electrolyte is frequently used to prepare AAO film with large pore diameter (typically $300 \mathrm{~nm}$ ), while the typical pore diameter in oxalic acid is about $50 \mathrm{~nm}$. Therefore, different corrosion properties are thought to lead to different variation trends of volume expansion factor.

It should be noted that the aforementioned corrosion test is only an approximate method, because it cannot fully reflect the dissolution effect during the anodization process. However, this approximate test undoubtedly shows that the corrosion phenomenon during anodization is non-ignorable. The following research shows that the oxide dissolution during anodization is also greatly affected by the electric field.

\subsection{Effect of anodization voltage and duration on volume expansion factor}

The influence of voltage on the volume expansion factor is shown in Fig. 7. It is obvious that the volume expansion factor gradually increases with voltage. There is an ideal linear relationship between voltage and volume expansion factor, especially for $4 \mathrm{~h}$ anodization and $6 \mathrm{~h}$ anodization. However, the linear relationship slightly worse when the anodization time reaches $10 \mathrm{~h}$. The least square method is used to determine the curve slope. With the prolongation of anodization duration, the curve slope gradually decreases, $0.014 \mathrm{~V}^{-1}$ for $2 \mathrm{~h}$ anodization, $0.013 \mathrm{~V}^{-1}$ for $6 \mathrm{~h}$ anodization, and $0.011 \mathrm{~V}^{-1}$ for $10 \mathrm{~h}$ 
anodization. A linear relationship between voltage and volume expansion factor has also been confirmed in the relevant literature [17, 24]. For instance, Vrublevsky et al. [17] reported a linear relationship between voltage and volume expansion factor, i.e., $\mathrm{k}=1.092+0.007 \mathrm{U}$ ( $\mathrm{k}$ : volume expansion factor; U: voltage $\mathrm{V} ; 20$ $\sim 50 \mathrm{~V}, 4 \mathrm{wt} \%$ oxalic acid, $20^{\circ} \mathrm{C}$ ). The difference between the linear formula in Fig. 7 and that reported in the literature [17] may be caused by different oxidation conditions. Although the voltage (20 $50 \mathrm{~V})$, electrolyte type (oxalic acid), concentration ( $4 \mathrm{wt} \%)$, and temperature $\left(20^{\circ} \mathrm{C}\right)$ are the same as this work, the sample size $(0.75 \mathrm{~cm} \times 0.75 \mathrm{~cm})$ and film thickness $(1.8 \mu \mathrm{m})$ used in the literature [17] are significantly different from those used in this work due to the different research purposes.

In Fig. 7, it is also found that the volume expansion factor is affected by anodization duration. However, to the best of our knowledge, the relationship between volume expansion factor and anodization duration is rarely mentioned in the relevant literature. Next, we discuss how the volume expansion factor changes with anodization duration under different voltages (Fig. 8). As shown in Fig. 8, under three voltages, with the prolongation of anodization duration, the volume expansion factor roughly shows a change trend of first rising and then falling (the latter half of the $40 \mathrm{~V}$ curve has a relatively small slope). Moreover, as the voltage increases, the time point at which the maximum volume expansion factor appears gradually shifts to the left. That is, the higher the voltage is, the earlier the peak value appears. In addition, as voltage increases, the absolute value of the curve slope gradually decreases in the rising stage of volume expansion factor, while increases in the falling stage.

As mentioned above, the film thickness growth is determined by the competition between electric fieldcontrolled oxidation and corrosion-controlled dissolution, as shown in Figs. 5 and 6. However, when other influencing factors are not considered, at the same acid concentration and temperature, the oxide corrosion rate in acidic solutions should be approximately constant and not change with time. The experiment shown in Fig. 9 also confirmed this conjecture. In Fig. 9, the AAO material (40 V, 6 h, 4 wt\% oxalic acid, $\left.20^{\circ} \mathrm{C}\right)$ is subjected to the corrosion treatment $\left(0 \mathrm{~V}, 4 \mathrm{wt} \%\right.$ oxalic acid, $\left.20^{\circ} \mathrm{C}\right)$ to investigate the alumina corrosion effect with time. It can be seen from Fig. 9 that the thickness loss (or quality loss) has a linear relationship with the corrosion duration. In other words, the corrosion rate is approximately constant when voltage $=0 \mathrm{~V}$. The contradiction between the constant corrosion rate and the first rising and then falling trend of volume expansion factor can be explained by field-assisted nature of AAO dissolution [21].

The actual anode surface temperature during anodization process was measured to investigate the fieldassisted nature of AAO dissolution. Four Al substrates were prepared, and the sample size was $3 \mathrm{~cm} \times 4.5$ $\mathrm{cm}$ for S1, $3 \mathrm{~cm} \times 9 \mathrm{~cm}$ for $\mathrm{S} 2,3 \mathrm{~cm} \times 4.5 \mathrm{~cm}$ for S3, and $3 \mathrm{~cm} \times 9 \mathrm{~cm}$ for S4, respectively. A thermocouple was fixed close to the Al plate by using waterproof tape. The other side of Al plate was exposed to the electrolyte. The oxidizable area of Al plate was adjusted by changing the coverage area of waterproof tape, as shown in Fig. 10. Another thermocouple was placed in the middle between the Al plate and the cathode to measure the electrolyte temperature. Samples S1 S4 were anodized in $4 \mathrm{wt} \%$ oxalic acid and at $20^{\circ} \mathrm{C}$, and the adopted voltage was $40 \mathrm{~V}$ for $\mathrm{S} 1,40 \mathrm{~V}$ for $\mathrm{S} 2,60 \mathrm{~V}$ for $\mathrm{S} 3$, and $60 \mathrm{~V}$ for S4. The actual anode surface temperature during anodization process was recorded online, as shown in 
Fig. 11. During the anodization process, the electrolyte temperature (E1 E4) is well maintained at about $20^{\circ} \mathrm{C}$, and no appreciable change is observed. However, the anode surface temperature is much higher than the electrolyte temperature, and a higher voltage produces a higher anode surface temperature. For example, the surface temperature of $S 2$ anodized at $40 \mathrm{~V}$ is about $40^{\circ} \mathrm{C}$, while the temperature of $\mathrm{S} 4$ anodized at $60 \mathrm{~V}$ is as high as $77^{\circ} \mathrm{C}$. It is considered that the high temperature of the local oxide is caused by the Joule-heating effect of oxidation reaction $[19,20]$. Although the electrolyte temperature remains almost constant during the anodizing process, the Joule-heating effect significantly increases the anode surface temperature, which thereby greatly promotes the AAO film dissolution (i.e., Joule heat-enhanced dissolution).

During the anodization process, as voltage, electrolyte temperature or electrolyte concentration increase, current (or current density) increases, and more $\mathrm{Al}$ is ionized into $\mathrm{Al}^{3+}$ ions, namely field-assisted ionization and thermally-enhanced ionization [19]. Simultaneously, the concentration of hydroxide and oxygen ions from the hydrolysis of the conjugate base of the acids also increases at the oxide/electrolyte interface [17]. As a result, more alumina is produced and leads to a larger volume expansion factor. However, when an excessively high voltage or electrolyte temperature is used, the Joule heat of oxidation will greatly increase the actual local oxide temperature by tens of degrees and accelerate the dissolution process, resulting in the decreased volume expansion factor (or its rising-rate slows down).

The effect of anodization duration on the expansion volume factor is discussed below. After the anodization for a long time, a large film thickness of tens of microns (long pore length) can be obtained. The diffusion distance of tens of microns and the small pore diameter of tens of nanometers limit the diffusion of ions into the pores (more precisely, the pore bottom). The ion concentration in the pores directly involved in the oxidation reaction decreases gradually, which inhibits the film growth rate. The electric field strength in the pore may also change due to the increase in resistance. In this case, in comparison with the effect of oxidation reaction on AAO film growth, the effect of Joule heat-enhanced dissolution becomes more prominent. The longer the oxidation time, the deeper the pores and the more obvious the limiting effect on film growth. Therefore, in the latter half of the test in Fig. 8, the volume expansion factor decreases with the prolongation of anodization duration. A higher voltage produces a stronger Joule heating effect, which makes the maximum value of volume expansion factor appear earlier. Moreover, as mentioned in Fig. 8, as voltage increases, the absolute value of the curve slope gradually increases in the falling stage of volume expansion factor. This phenomenon is attributed to the fact that the high voltage intensifies the effect of Joule heat-enhanced dissolution. This is also believed to be a reasonable explanation for the lower slope of the hollow-lower-triangle curve (in Fig. 7, anodized for $10 \mathrm{~h}$ ) than those anodized for the shorter time. In addition, this also accounts for the non-linear relationship between film thickness and anodization duration, as shown in Fig. 2.

We do not have enough evidence to explain the increased volume expansion factor shown in the first half of the test in Fig. 8. It is speculated that this may be related to the diffusion of $\mathrm{Al}^{3+}$ ions in pores. Part of $\mathrm{Al}^{3+}$ ions produced by aluminum ionization reacts with $\mathrm{O}^{2-}$ to form alumina. Another part of $\mathrm{Al}^{3+}$ diffuses to the oxide/electrolyte interface, and a large number of $\mathrm{Al}^{3+}$ ions appear near the interface. These $\mathrm{Al}^{3+}$ 
ions react with $\mathrm{OH}^{-}$ions to form negatively-charged aluminum hydrate and deposit on the anode. It is supposed that this deposition also contributes to the volume expansion factor to some extent. When the film thickness is relatively small, some $\mathrm{Al}^{3+}$ ions may directly diffuse into the electrolyte bulk, instead of reacting with $\mathrm{OH}^{-}$ions and depositing on the anode. Appropriate pore length may limit the $\mathrm{Al}^{3+}$ ion diffusion into the electrolyte bulk through the confinement effect. It is speculated that this is one of the reasons why the volume expansion factor increases with the anodization duration prolongation in the first half of the test in Fig. 8. Further research is in progress.

In addition, in Fig. 11, the comparison between S1 and S2 (or S3 and S4) shows that as the sample size increases, the Joule heating effect becomes more obvious, because the larger sample size shows a higher surface temperature. For example, under the same voltage (60 V), the surface temperature of S3 (3 $\mathrm{cm} \times 4.5 \mathrm{~cm})$ is about $53^{\circ} \mathrm{C}$, while that of $S 4(3 \mathrm{~cm} \times 9 \mathrm{~cm})$ is about $77^{\circ} \mathrm{C}$. In other words, the larger the sample size, the higher the voltage, and the more significant the Joule-heating effect. Note that S1 S4 samples used in Fig. 11 were anodized under a single-sided anodization model. In the case of doublesided model, the Joule-heating effect should be more obvious. It is understandable that under the same conditions, the growth rate of the large-sized AAO film is higher than that of the small-sized AAO film in the first half of the preparation process because the Joule-heating effect accelerates the film growth. However, in the subsequent stage, since Joule heat promotes both the growth rate and the dissolution rate, the growth rate of the large-sized AAO film is slower than that of the small-sized AAO film. Eventually, an equilibration is achieved between growth and dissolution. In this process, the Joule heat also acts as a catalyst to speed up the process and shorten the equilibration time, especially when high voltage is applied. According to the above discussion, how to control heat transfer is considered to be the key to manufacture a thick and large-sized AAO film. Even if the conventional anodization conditions (electrolyte type, concentration, temperature, voltage/current density, duration) are the same, sample size, electrolyte capacity, circulating cooling flow rate and other heat transfer-related conditions will greatly affect the AAO film growth, which are often ignored in the relevant literature. Relevant literature has investigated the effect of aluminum purity, which is also considered to be associated with the Jouleheating effect. Generally, because a small amount of impurities in the aluminum substrate (generally less than $1 \%$ ) significantly changes the Joule heat of anodization, different pore morphologies [20] or film thickness growth rates [15] are obtained on aluminum substrates with different purity.

Based on the research of this work, for preparing a thick and large-sized AAO film, the anodization voltage and duration are considered to be more effective and easily-controlled parameters than electrolyte temperature or concentration. A voltage of about $30 \sim 50 \mathrm{~V}$ and a duration of $2 \sim 10 \mathrm{~h}$ are preferred preparation parameters, because the film thickness has a linear relationship with the voltage or duration. Under these conditions, a maximum thickness of about $100 \mu \mathrm{m}$ can be obtained, and the ordered pore structure is well retained, which provides a favorable foundation for further modifying the AAO material as a catalyst support.

\section{Conclusions}


The film thickness increases exponentially with temperature $\left(5 \sim 30^{\circ} \mathrm{C}\right)$, and increases approximately linearly with voltage $(20 \sim 60 \mathrm{~V})$, duration $(<6 \mathrm{~h})$ or concentration $(2 \sim 8 \mathrm{wt} \%)$. In comparison with temperature, voltage or duration, the influence of concentration on film thickness is relatively weak. The volume expansion factor gives a first rising and then falling trend with temperature $\left(5 \sim 30^{\circ} \mathrm{C}\right)$ or duration $(2 \sim 16 \mathrm{~h})$, while it has a nearly linear trend with voltage $(40 \sim 60 \mathrm{~V})$ or concentration $(2 \sim 8 \mathrm{wt} \%)$. The volume expansion factor increases with the intensified electric field, while its decrease is attributed to the Joule heat-enhanced dissolution. In the case of large film thickness $(>20 \mu \mathrm{m})$, it is suggested that the pore confinement effect may be one of the reasons for the change of volume expansion factor with anodization duration.

In addition, it is believed that in addition to the conventional anodization conditions (electrolyte type, concentration, temperature, voltage/current density and duration), the heat transfer related conditions (such as sample size, electrolyte capacity, circulating cooling flow rate, etc.) will also greatly affect the AAO film growth.

\section{References}

1. C. Fukuhara, A. Igarashi, J. Chem. Eng. Jpn. 37, 415 (2004)

2. R.M. Heck, R.J. Farrauto, Appl. Catal. A. Gen 221, 443 (2001)

3. R.R. Hong, J.T. Feng, Y.F. He, D.Q. Li, Chem. Eng. Sci. 135, 274 (2015)

4. E.L. Reddy, H.C. Lee, D.H. Kim, Int. J. Hydrog. Energy 40, 2509 (2015)

5. N.N. Qiao, Y.L. Nong, N. Liu, Y. Liang, Mater. Chem. Phys 225, 458 (2019)

6. L. Zhang, H.L. Chu, H. Qu, Hydrog. Energy 43, 3077 (2018)

7. Z.B. Rui, Ch.Y. Chen, Y.B. Lu, H.B. Ji, Chinese J. Chem. Eng 22, 882 (2014)

8. H. Kameyama, Suiso, Energy. Shisutemu 20, 16 (1995). (in Japanese)

9. L. Zhou, Y. Guo, M. Yagi, M. Sakurai, Int. J. Hydrog. Energy 34, 844 (2009)

10. Y. Guo, L. Zhou, H. Kameyama, Chem. Eng. J. 168, 341 (2011)

11. L. Zhou, Y. Guo, J.-M. Basset, H. Kameyama, Chem. Commun. 51, 12044 (2015)

12. C. Zhang, Y. Pu, F. Wang, Chinese. J. Chem. Eng 28, 1311 (2020)

13. M. Khaled, N.M. Chahrour, M.R. Ahmed, Hashim, Superlattices Microstruct. 88, 489 (2015)

14. Y. Ren, K. Zhang, Mater. Lett 63,1925 (2009)

15. G.D. Leszek Zaraska, Sulka, Marian Jaskuła, Surf. Coat. Tech 205, 2432 (2010)

16. S. Nevin Ta, saltın, N. Öztürk, Kılınç, Appl. Phys. A 95, 781 (2009)

17. I. Vrublevsky, V. Parkoun, J. Schreckenbach, G. Marx, Appl. Surf. Sci 220, 51 (2003)

18. G. Knörnschild, A.A. Poznyak, A.G. Karoza, Surf. Coat. Tech 275, 17 (2015)

19. T.-T. Kao, Y.-C. Chang, Appl. Surf. Sci 288, 654 (2014)

20. C.K. Chung, W.T. Chang, M.W. Liao, H.C. Chang, Mater. Lett 88, 104 (2012) 
21. A. Belwalkar, E. Grasing, W. Van Geertruyden, J. Membrane. Sci 319, 192 (2008)

22. F. Behzadi, M. Moradi, H.R. Karimi-Alavijeh, A. Gharavi, Vac 99, 204 (2014)

23. GuangTao GuoLiang Shang, Fei, Mater. Lett 110, 156 (2013)

24. F. Zhou, A. Baron-Wieche'c, S.J. Garcia-Vergara, Electrochim. Acta 59, 186 (2012)

\section{Figures}
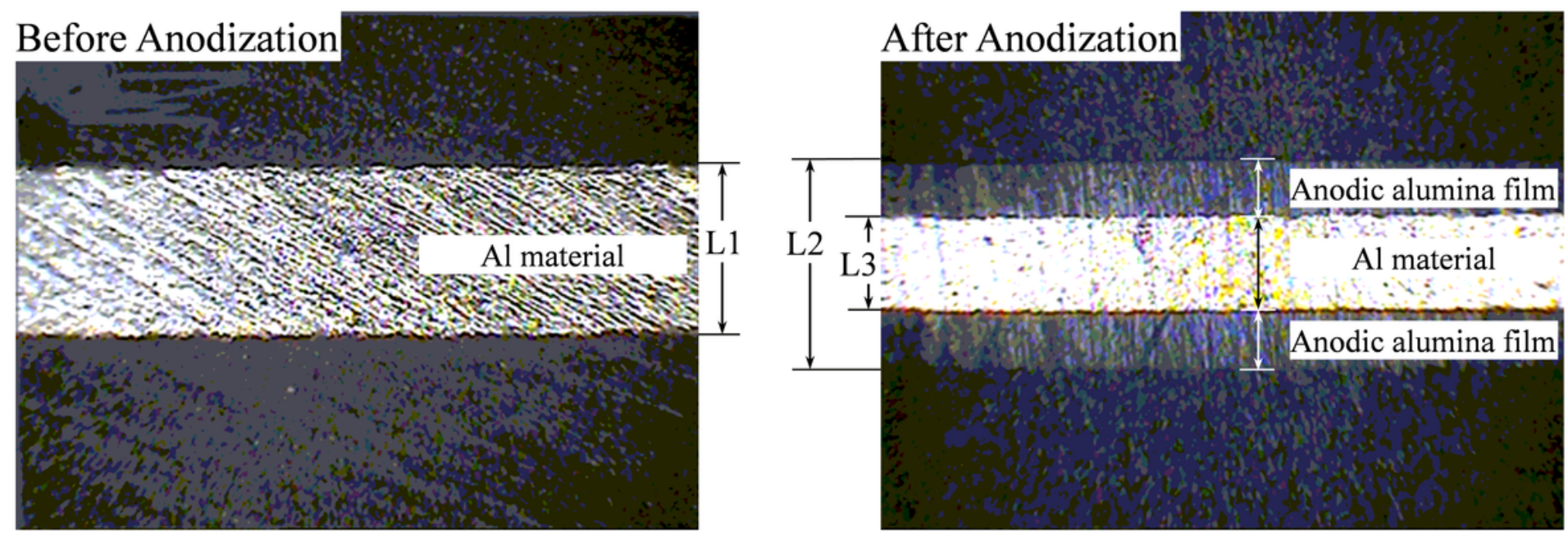

Figure 1

Cross-sectional photos of AAO samples before and after anodization 


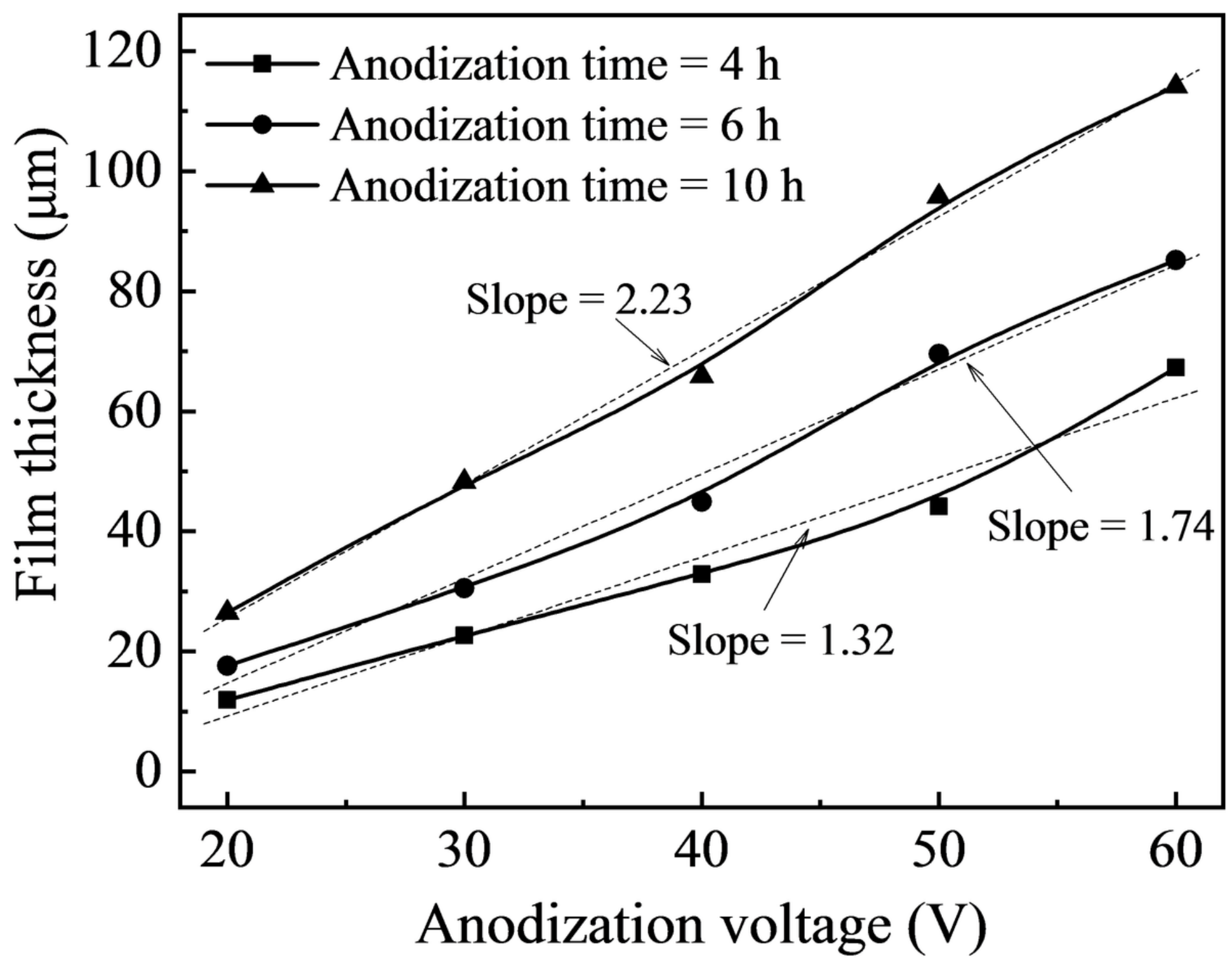

Figure 2

AAO film thickness versus anodization voltage under different anodization duration $\left(20^{\circ} \mathrm{C}, 4 \mathrm{wt} \%\right.$ oxalic acid) 


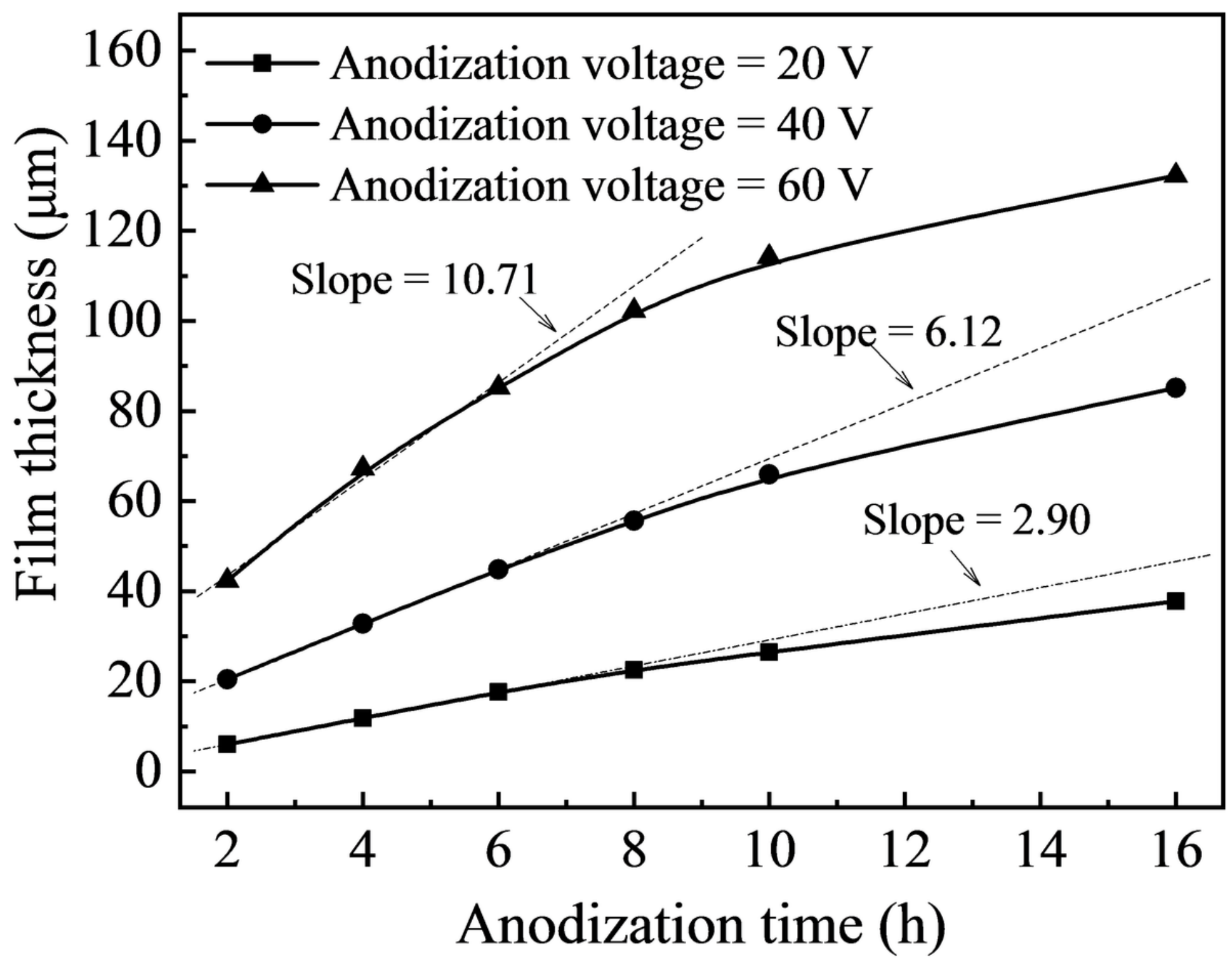

Figure 3

AAO film thickness versus anodization time under different anodization voltages $\left(20^{\circ} \mathrm{C}, 4 \mathrm{wt} \%\right.$ oxalic acid) 


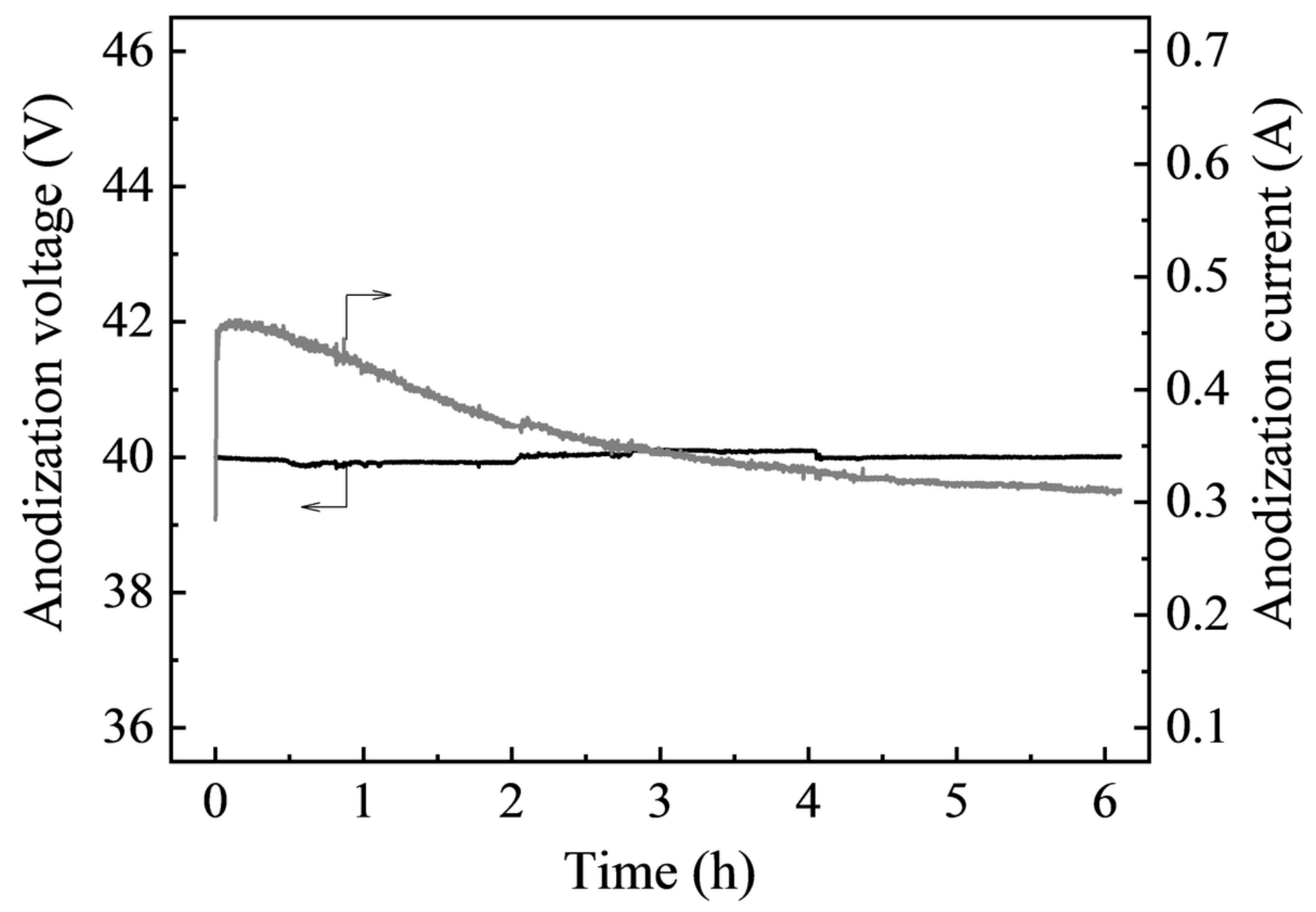

Figure 4

Anodization current or voltage as a function of anodization time $\left(40 \mathrm{~V}, 20^{\circ} \mathrm{C}, 4 \mathrm{wt} \%\right.$ oxalic acid) 


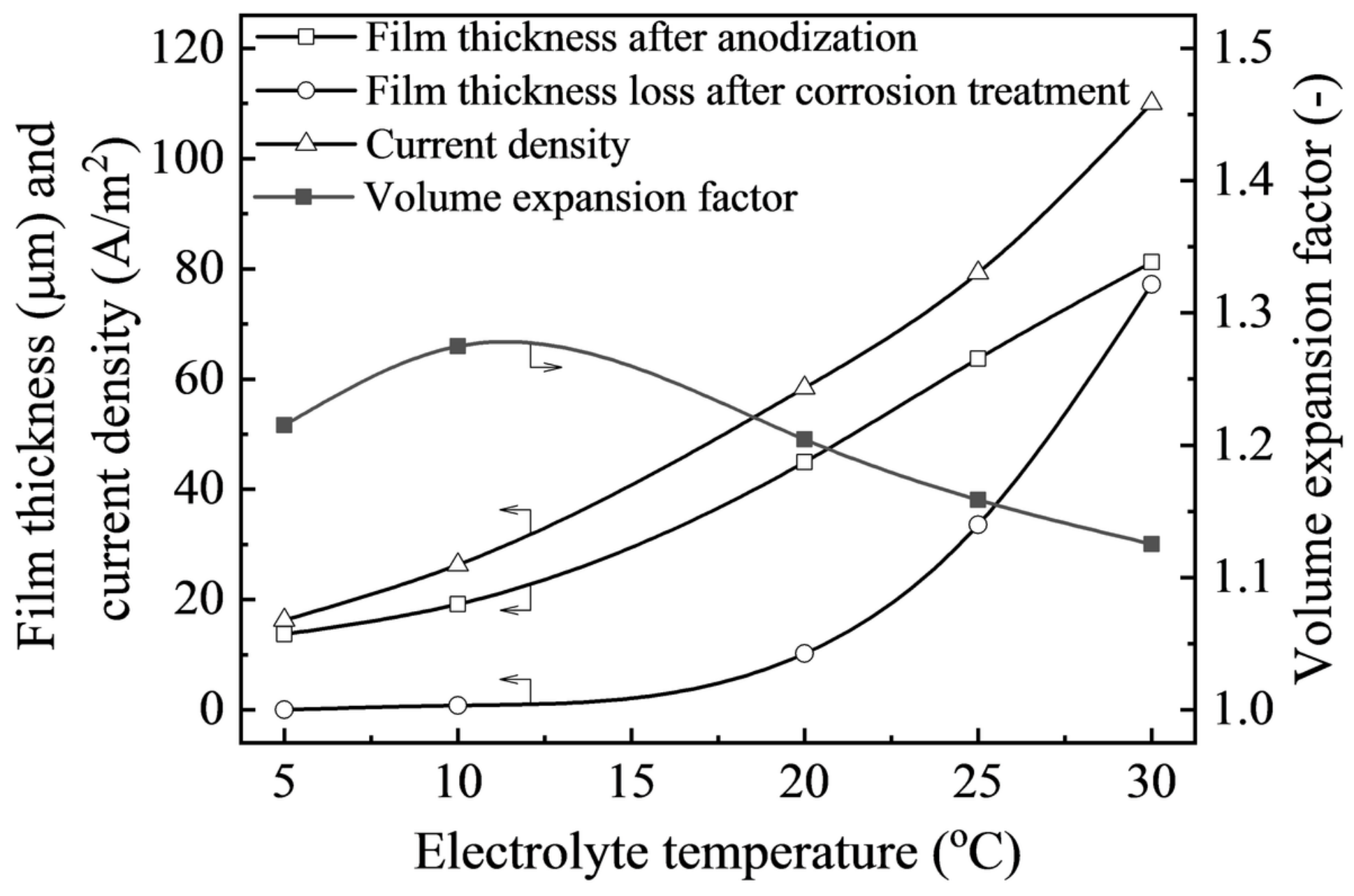

Figure 5

AAO Film thickness after anodization, film thickness loss after corrosion treatment, volume expansion factor and current density versus electrolyte temperature (40 V, 6 h, 4 wt\% oxalic acid) 


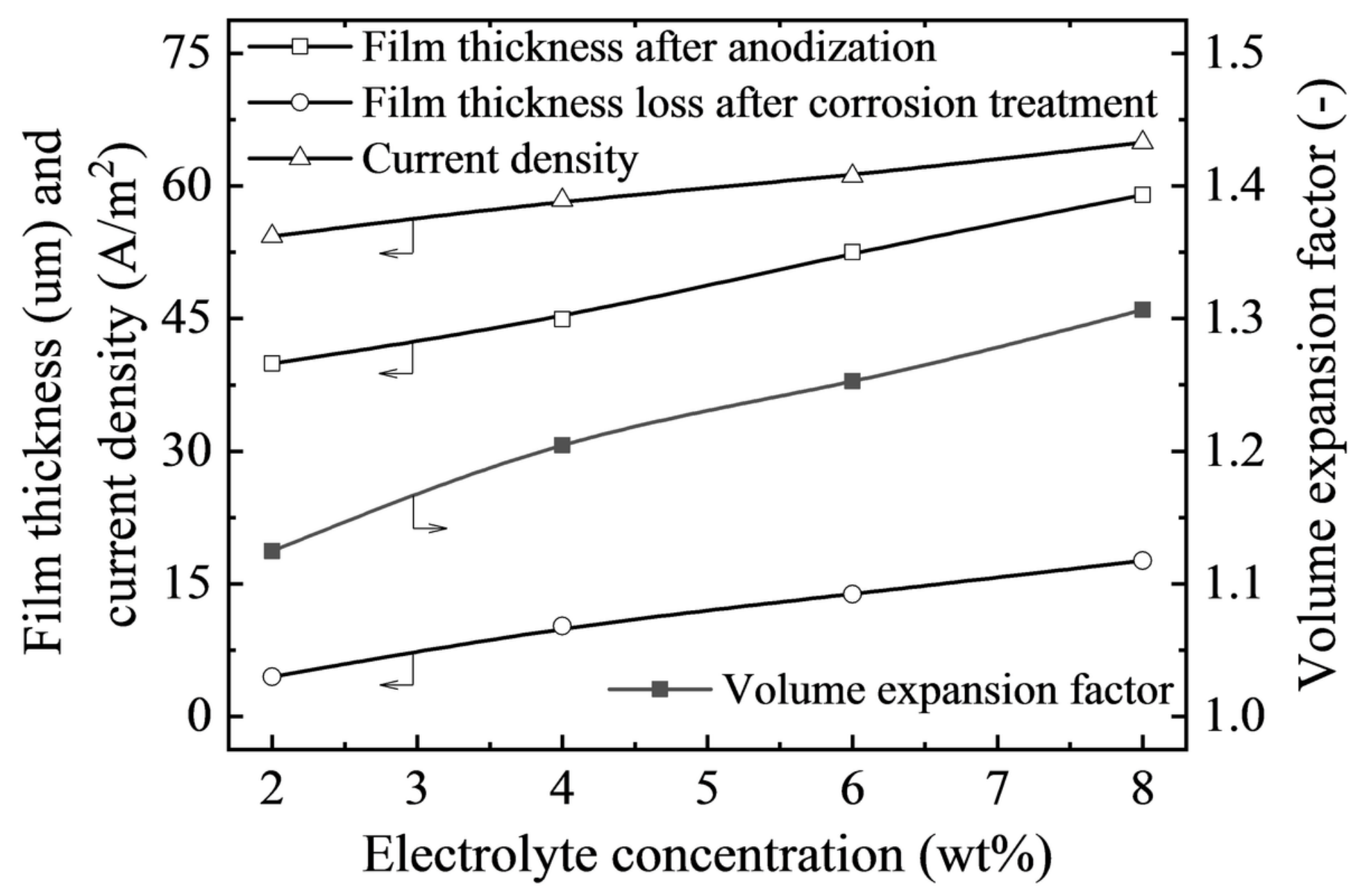

Figure 6

AAO Film thickness after anodization, film thickness loss after corrosion treatment, volume expansion factor and current density versus electrolyte concentration $\left(40 \mathrm{~V}, 6 \mathrm{~h}, 20^{\circ} \mathrm{C}\right)$ 


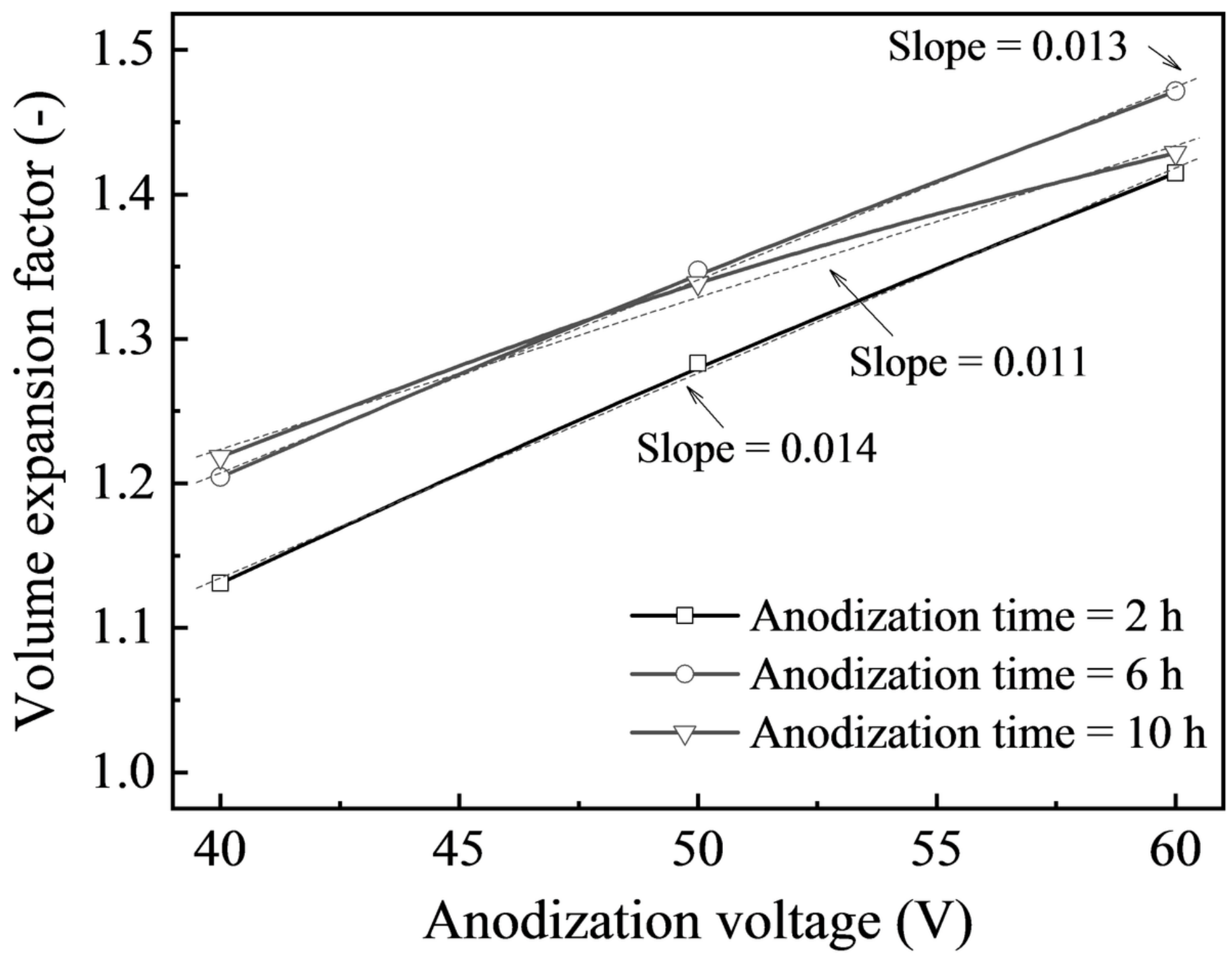

Figure 7

Volume expansion factor versus anodization voltage under different anodization duration $\left(20^{\circ} \mathrm{C}, 4 \mathrm{wt} \%\right.$ oxalic acid) 


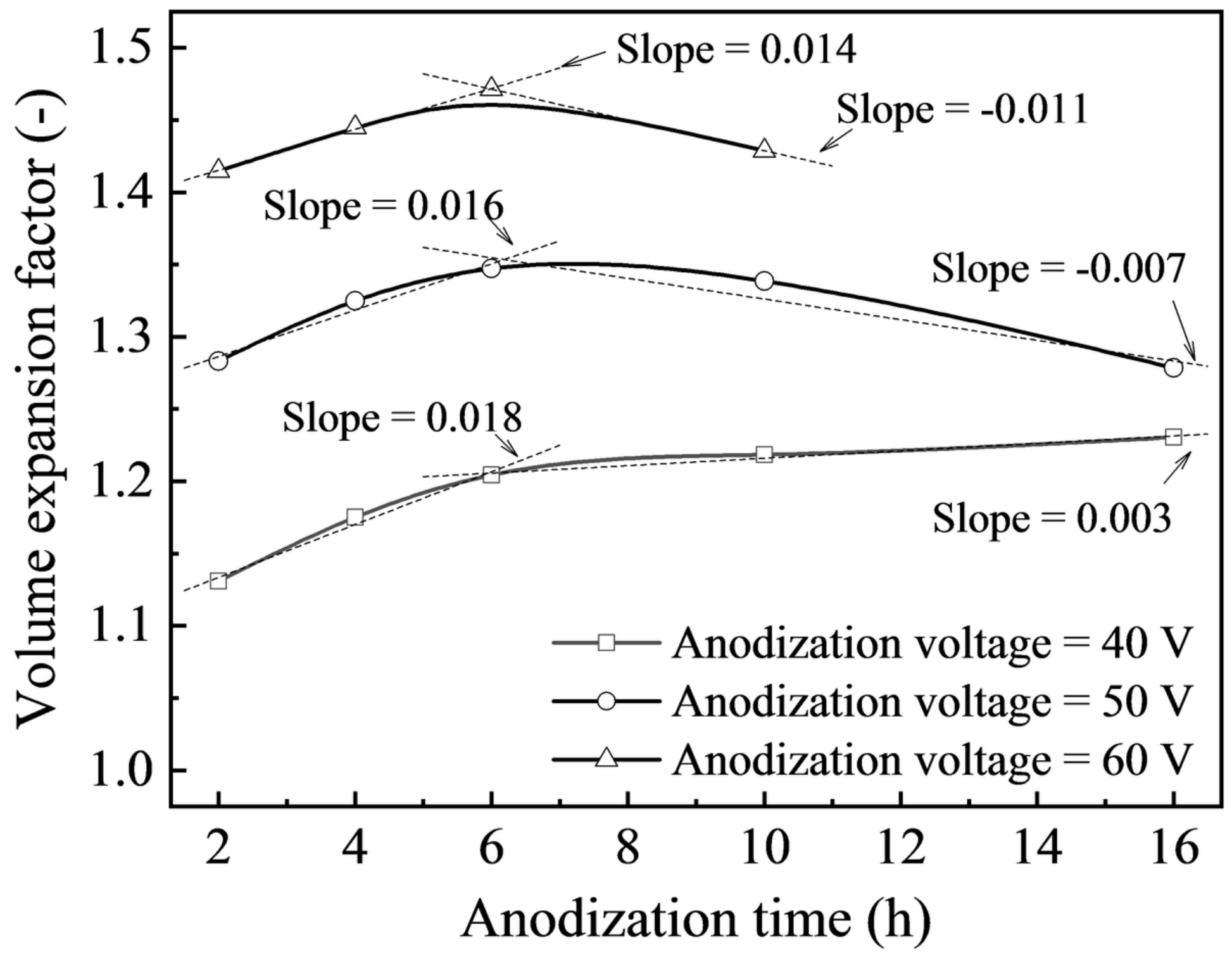

Figure 8

Volume expansion factor versus anodization time under different anodization voltage $\left(20^{\circ} \mathrm{C}, 4 \mathrm{wt} \%\right.$ oxalic acid) 


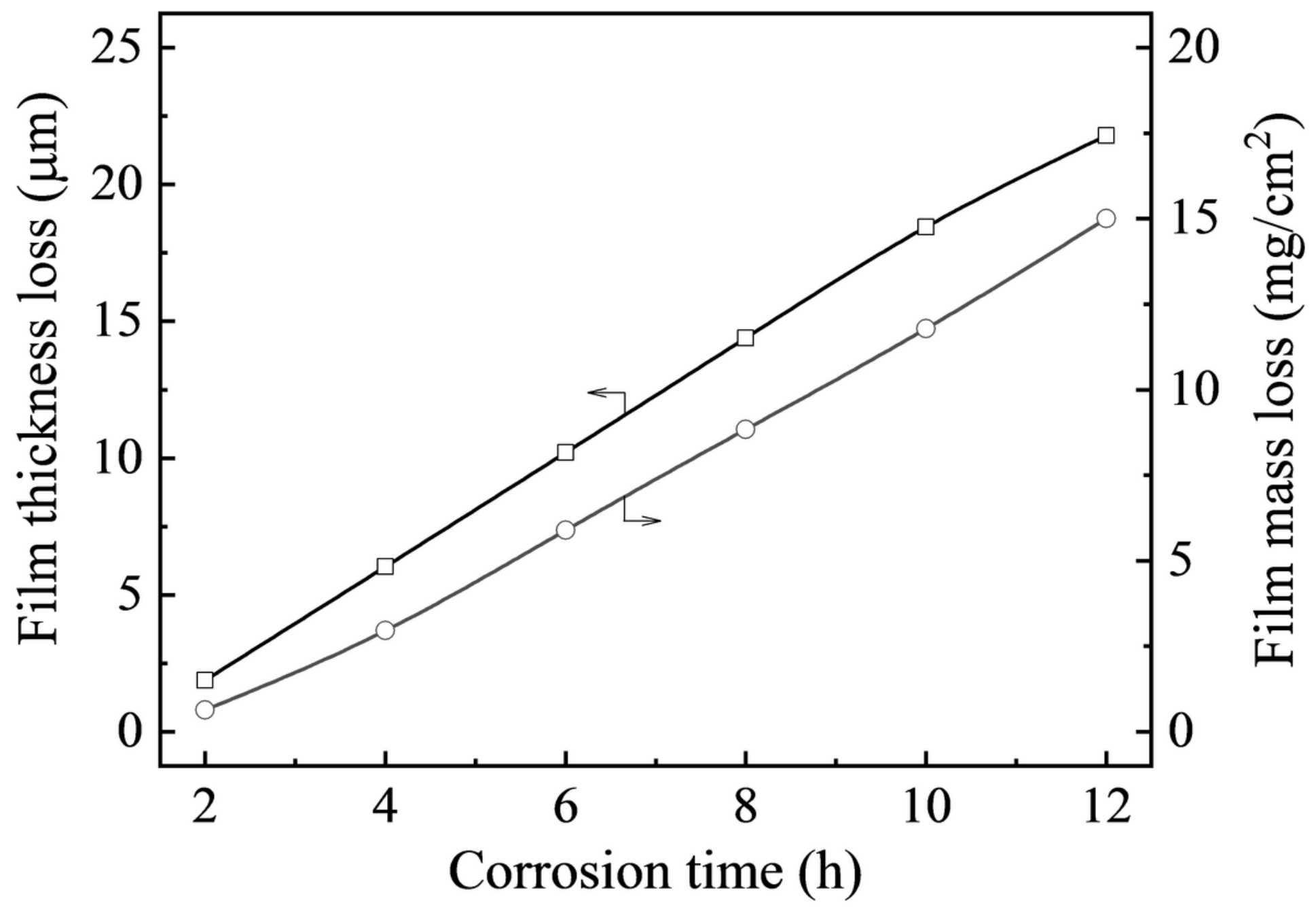

Figure 9

Film thickness loss or mass loss versus corrosion time $\left(0 \mathrm{~V}, 20^{\circ} \mathrm{C}, 4 \mathrm{wt} \%\right.$ oxalic acid $)$ 


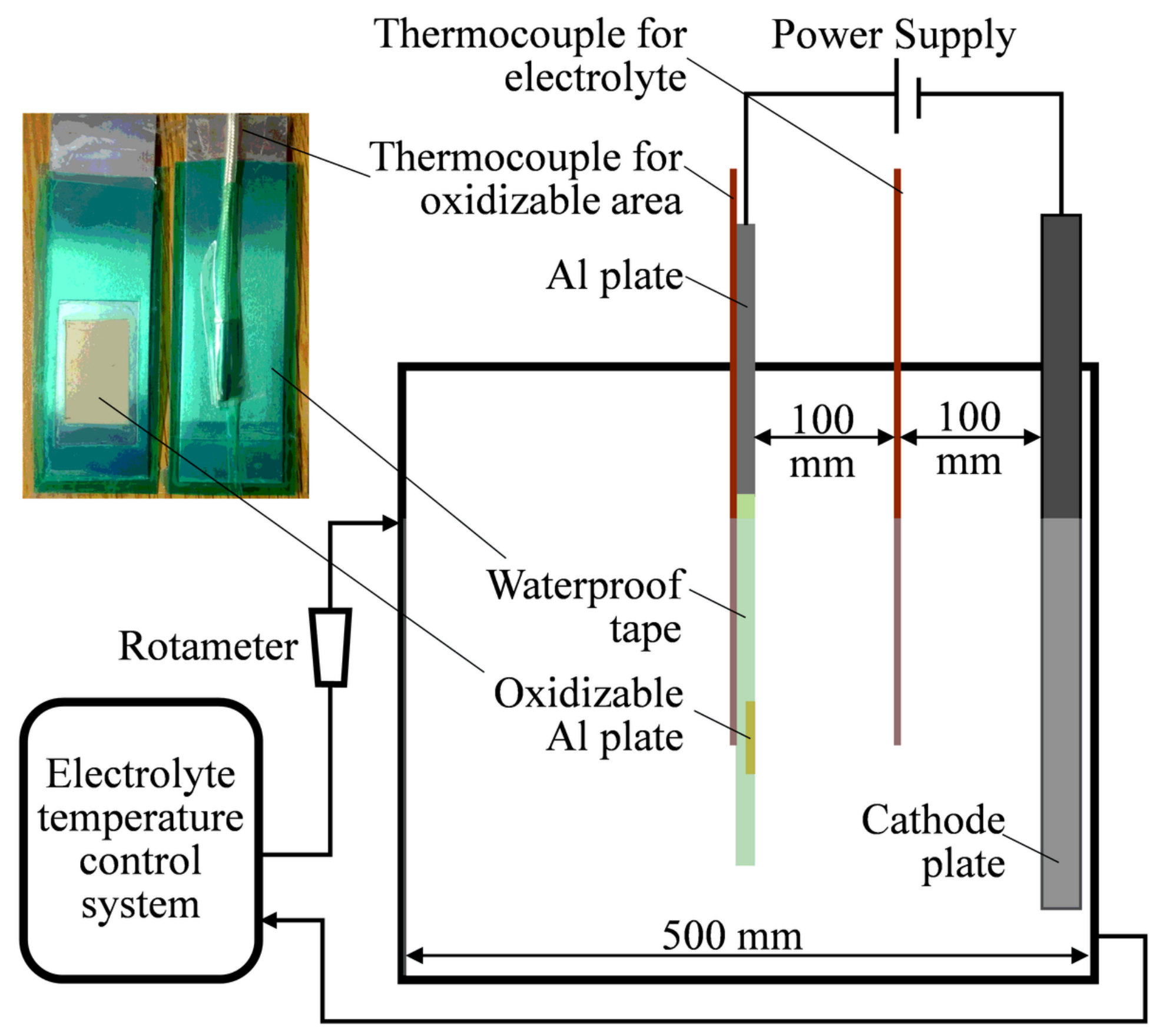

Figure 10

Schematic diagram of the experiment for testing anode surface temperature 


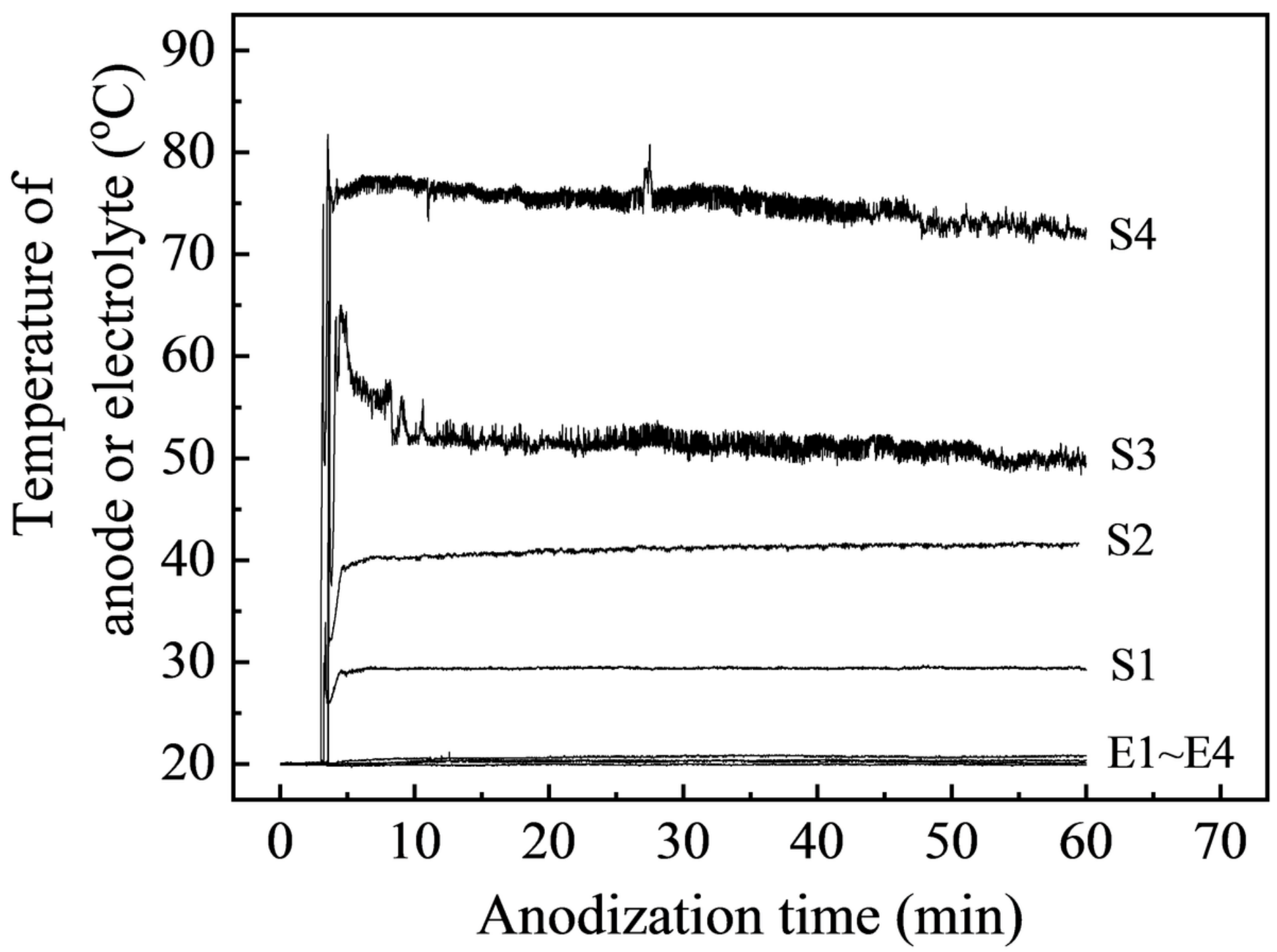

Figure 11

Anode surface temperature during anodization process $\left(20^{\circ} \mathrm{C}\right.$, 4 wt\% oxalic acid; Sample S1: $3 \mathrm{~cm} \times 4.5$ cm, 40 V; Sample S2: $3 \mathrm{~cm} \times 9 \mathrm{~cm}, 40$ V; Sample S3: $3 \mathrm{~cm} \times 4.5 \mathrm{~cm}, 60$ V; Sample S4: $3 \mathrm{~cm} \times 9 \mathrm{~cm}, 60$ V; E1-E1: electrolyte temperature corresponding to sample S1-S4) 